\title{
Profile of mecasermin for the long-term treatment of growth failure in children and adolescents with severe primary IGF-I deficiency
}

This article was published in the following Dove Press journal:

Therapeutics and Clinical Risk Management

15 July 2009

Number of times this article has been viewed

\section{Danilo Fintini \\ Claudia Brufani \\ Marco Cappa}

Endocrinology Unit, "Bambino Gesù” Children's Hospital-IRCCS, Rome, Italy
Correspondence: Marco Cappa Chief of Endocrinology Unit,"Bambino Gesù” Children's Hospital-IRCCS, L.go S.Onofrio, 4, 00165 , Rome, Italy Tel +3906 68592020

$\mathrm{Fax}+390668593427$

Email marco.cappa@opbg.net
Abstract: Growth hormone insensitivity syndrome (GHI) or insulin-like growth factor-1 (IGF-1) deficiency (IGFD) is characterized by deficit of IGF-1 production due to alteration of response of growth hormone $(\mathrm{GH})$ receptor to $\mathrm{GH}$. This syndrome is due to mutation of $\mathrm{GH}$ receptor or IGF-1 gene and patients affected showed no response to GH therapy. The only treatment is recombinant IGF-1 (mecasermin), which has been available since 1986, but approved in the United States by the US Food and Drug Administration only in 2005 and in Europe by the European Medicines Agency in 2007. To date, few studies are available on long-term treatment with mecasermin in IGFD patients and some of them have a very small number of subjects. In this review we discuss briefly clinical features of severe primary IGFD, laboratory findings, and indications for treatment. Results of long-term therapy with rhIGF1 (mecasermin) in patients affected by severe primary IGFD and possible side effects are explained.

Keywords: mecasermin, therapy, Laron syndrome, IGF-1

\section{Introduction}

Growth hormone insensitivity (GHI) comprises a range of disorders characterized by resistance to growth hormone $(\mathrm{GH})$. It is well known that insulin-like growth factor-1 (IGF-1) plays a key role in mediating GH action on human growth. ${ }^{1} \mathrm{GHI}$ is characterized by deficiency of either production or peripheral action of IGF-1 on linear growth. Therefore, primary GHI has also been described as IGF deficiency (IGFD). ${ }^{2}$

The only therapy to date for treatment of severe IGFD is recombinant IGF-1 (rhIGF1) or mecasermin (Increlex ${ }^{\mathrm{TM}}$; Tercica, Brisbane, CA, USA) which has been available since 1986, but was approved as an orphan drug by the US Food and Drug Administration (FDA) in 2005 and by the European Medicines Agency (EMEA) in 2007.

The initial manufacturer (Fujisawa Pharmaceuticals Corp., now Astellas Pharma Inc., Tokyo, Japan) had developed mecasermin in Japan and marketed it as Somazon. Somazon was launched in 1995 for the treatment of insulin-resistant diabetes and primary IGFD. Tercica acquired a worldwide license (excluding Japan) for the commercialization of mecasermin in April 2005..$^{3,4}$

Another recombinant form of IGF-1 was developed by Chiron Corp (Emeryville, CA, USA) in collaboration with Cephalon Inc. (Frazer, PA, USA) for the treatment of amyotrophic lateral sclerosis, but the product was abandoned by early $2000 .^{3}$

The results in this review are based on data obtained by studies with mecasermin as available from 2005 by Tercica (Increlex ${ }^{\mathrm{TM}}$ ).

In this review we briefly analyze the etiology and clinical findings of severe primary IGFD, the role of long term therapy with rhIGF-1 and prospects for the future. 


\section{Etiology of primary IGF-I deficiency}

GHI can be divided into primary or congenital and secondary or acquired as described in Table 1. Secondary or acquired GHI is characterized by GH-IGF-1 axis dysfunction due to malnutrition, liver diseases, catabolic illness, or neutralizing antibodies to growth hormones, affecting IGF-1 production and action. In these conditions the GH secretion is normal but peripheral effects is compromised with low or very low levels of serum IGF-1, due to a type of GH resistance or more often to alteration of IGF-1 production from the liver. ${ }^{2,10}$

Otherwise, primary GHI or IGFD is due to congenital resistance to GH action with low or absent peripheral IGF-1. ${ }^{2}$ This syndrome, also known as Laron syndrome, was first described by Laron in the late 1960s as pituitary dwarfisms with high serum $\mathrm{GH} .{ }^{2}$ It is a very rare syndrome resulting from genetic abnormality of GH receptor, mainly occurring in patients with high consanguinity. ${ }^{2,5}$

Over 250 cases of defects of GH receptors (GHR) have been described to date and over 60 of them are due to GHR gene mutations affecting the capacity of the receptor of binding, dimerizing, migrating, or initiating postreceptor cascade. ${ }^{6}$ Also mutations in STAT- $5 b,{ }^{7} I G F-1,{ }^{8}$ that leads to a bioinactive IGF-1, and acid labile subunit $(A L S)^{9}$ genes, have been reported.

\section{Clinical characteristics of primary IGF-I deficiency}

Patients affected by primary GHI generally show normal-low birth length and weight, with progressive severe postnatal growth failure resulting in extremely short adult stature. ${ }^{2,11}$

Table I Etiologic classification of GH insensitivity

Primary GH insensitivity syndrome (congenital)

$\mathrm{GH}$ receptors defects (extracellular, transmembrane, or intracellular mutations)

Abnormalities of GH signal transduction (STAT5B mutations)

ALS defect

Bioinactive IGF-I

Primary defects of synthesis and action of IGF-I (IGF-I mutations or IGF-I receptor mutations)

Secondary GH insensitivity diseases (acquired)

$\mathrm{GH}$-neutralizing antibodies

Malnutrition

Liver disease

Catabolic state

Chronic inflammatory and nutritional disorders

Abbreviations: ALS, acid labile subunit; GH, growth hormone; IGF-I, insulin-like growth factor-I.
Clinical features of GH deficiency are present, ${ }^{1}$ but a more severe impairment in growth characterizes this syndrome. Final height in untreated IGFD adults is $4-10$ standard deviation score (SDS) below the mean height.

In early childhood, affected individuals appear extremely short and obese with thin bones and undeveloped muscles. In adulthood, they usually have acromicria and disproportional upper/lower segment ratio with short limbs for the trunk size. These patients have characteristic midfacial hypoplasia with protruding forehead, saddle nose, and sunset look. Children and some adults, especially women, show a very high-pitched voice. ${ }^{2}$ In adulthood, osteoporosis can be present but this can be considered an artifact due to the small bone size in these patients. Indeed when values of bone density are normalized for size of the patients, the values becomes normal for age and sex. ${ }^{12,13}$

Genitalia are small since birth and puberty is usually delayed, more often in boys than in girls, with testicular enlargement beginning between 13 and 16 years in boys and menarche occurring between 13 and 15 years in girls. In early adulthood they do not show difficulties with reproduction. ${ }^{14}$

Longevity has been reported to be normal in the largest cohort studied to date. ${ }^{15-17}$

\section{Laboratory findings of primary IGF-I deficiency}

Neonates and babies with primary IGFD suffer hypoglycemia that continues through childhood and young adulthood. Before the age of six years, children show insulin nonresponsiveness. The response to hypoglycemia becomes normal during puberty when affected subjects develop adequate counter-regulatory mechanisms. ${ }^{2,14}$ Some patients may experience also glucose intolerance and diabetes later in life. ${ }^{18}$

IGF-1 levels are very low or undetectable with high or normal GH levels. Moreover, overnight GH pulses have been described very high, with peak values of $200-300 \mathrm{ng} / \mathrm{mL}$ $(\mu \mathrm{g} / \mathrm{L})$. The number of $\mathrm{GH}$ pulses, the response to exogenous stimuli as arginine, insulin hypoglycemia, or suppression with glucose administration, somatostatin, or glucocorticoids are always normal. ${ }^{2,14,20}$ Despite the high GH serum level, these patients show normal pituitary gland size.

Serum IGF-binding protein 3 (IGFBP-3) values are always low.

In severely short patients with normal GH response to provocative test, and additionally extremely low IGF-1 and/or IGFBP-3, an IGF-1 generation test can be helpful to confirm the diagnosis of IGFD. The IGF-1 generation test assesses the 
capacity of the liver to produce IGF-1 after administration of exogenous rhGH. The proposed dose of rhGH for the test is $0.033 \mathrm{mg} / \mathrm{kg} / \mathrm{day}$ for four consecutive days. The diagnosis of GHI is confirmed when there is an inadequate increment of IGF-1 and IGFBP-3 on the fifth day. ${ }^{19,21}$

The cut-off of post-stimulated IGF-1 for the diagnosis of GHI is still debated, with different authors proposing different cut-off points. Controversy is present in the literature regarding the appropriate dose of rhGH used in the test. Some authors debate that $0.033 \mathrm{mg} / \mathrm{kg}$ is too high a dose to identify mild GHI forms and suggested that a low-dose IGF-1 generation test $(0.011 \mathrm{mg} / \mathrm{kg}$ of $\mathrm{rhGH}$ for four days $)$ may be more useful in diagnosis of mild cases. ${ }^{22}$ However, a positive response to the test can be considered an increment of IGF-1 or IGFBP-3 more than twice the coefficient of variation of the assay used. ${ }^{23}$ The test identifies almost all the forms of primary GHI.

\section{Indications for treatment of severe IGF-I deficiency}

In 2005, the FDA approved the use of rhIGF1 (mecasermin): "Long term treatment of growth failure in children with severe primary IGFD due to mutation of the GHR or post-GHR signaling pathway, and the development of GH-inactivating antibodies in children with GH gene deletion. Severe primary IGFD patients with height SDS less than or equal to -3 , basal IGF-1 SDS less than or equal to -3 , and normal or elevated GH concentration. These patients are not GH-deficient, and therefore, they cannot be expected to respond adequately to exogenous GH treatment. rhIGF1 is not intended for use in subjects with secondary forms of IGF-1 deficiency, such as $\mathrm{GH}$ deficiency, malnutrition, hypothyroidism, or chronic treatment with pharmacologic doses of anti-inflammatory steroids. Thyroid and nutritional deficiencies should be corrected before initiating rhIGF-1. rhIGF-1 is not a substitute for GH." 17,19

In 2007, the EMEA approved the use of rhIGF1 for "the long term treatment of growth failure in children and adolescents with severe primary IGFD. Severe IGFD is defined by height SDS score $<-3$; basal IGF-1 levels below the 2.5 percentile for age and gender; GH sufficiency; exclusion of secondary forms of IGFD, such as malnutrition, hypothyroidism, or chronic treatment with pharmacologic doses of anti-inflammatory steroids. Severe primary IGFD includes patients with mutations in the $G H R$, post-GHR signaling pathway, and IGF-1 gene defects; they are not GH-deficient, and therefore, they cannot be expected to respond adequately to exogenous $\mathrm{GH}$ treatment. It is recommended to confirm the diagnosis by conducting an IGF-1 generation test." 19

These conditions are very rare and can affect at most several hundred children worldwide. ${ }^{4,17,24}$ For this reason many of the definition of severe primary IGFD adopted till now are usually ambiguous, derived by small groups of patients or personal experience and can be manipulated for marketing purposes.

In these definitions, certain items important for evaluation of children with short stature are not considered, such as bone age, parental height, and growth velocity. In this way some of the diagnoses of IGFD, especially in younger children, can be not real because of variability and usually low levels of serum IGF-1 in this age. On the other hand the variability between laboratories in analyzing IGF-1 levels and the high level of post-sampling proteolysis of IGF-1 make the diagnosis of severe IGFD more difficult. ${ }^{25,26}$

However, it has to be considered that, when using the FDA and EMEA definitions of severe IGFD, there is no risk of not treating patients affected by the disease. Indeed, when using these definitions as indication for rhIGF1 treatment, all patients affected by severe IGFD will receive the correct therapy.

\section{Treatment of severe primary IGF-I deficiency}

The only effective treatment for primary IGFD is replacement therapy with rhIGF1. ${ }^{2}$ Even if the drug has been available since 1986, for many years its use had been very restricted and only a small number of patients have been treated with the adequate therapy.

Equimolar complex of rhIGF1 and rhIGF-binding protein 3 (rhIGF-1/rhIGFBP3; Mecasermin Rrinfabate, Iplex; Insmed, Glen Allen, VA, USA) was also approved by the US FDA in 2005, ${ }^{4,16}$ but was withdrawn in the US in March 2007 due to a legal settlement and is not longer available for use in growth-related therapy.

Since the 1990s, clinical trials on rhIGF1 therapy in patients affected by confirmed or suspected GHR defects have been conducted. The first was in Israel where the original Laron dwarf was identified; ${ }^{27}$ the second in Ecuador where the largest cohort of GHI patients was studied; ${ }^{28}$ the third in Europe $;^{29}$ and the fourth in North America. ${ }^{30,31}$ All of these studies, except for the Ecuadorian one, were uncontrolled.

All data were highly consistent with good increment of growth rate during the first year of treatment. Growth velocity increased of $4.3 \mathrm{~cm} /$ year in the European and North America studies ${ }^{29-31}$ and $5.6 \mathrm{~cm} /$ year in the Ecuadorian study, compared 
to baseline. ${ }^{28}$ These three studies used the same amount of rhIGF1, with twice daily administrations. In the Israel study the first year growth velocity was only of $3.6 \mathrm{~cm} /$ year, probably due to the single injection of a comparable total daily dose. ${ }^{27}$

The dosage used in the different studies ranged from 40 to $120 \mu \mathrm{g} / \mathrm{kg}$ twice a day in the European and Ecuadorian studies, to $120 \mu \mathrm{g} / \mathrm{kg}$ twice a day, after the first year of therapy, in the North America study. ${ }^{29-31}$

A modest dose-dependent effect was observed especially during the first year of therapy. Moreover, the growth velocity rate showed a progressive attenuation after the first year, except in the Ecuadorian study, that showed less difference compared to the other studies between the first and the second year of therapy. ${ }^{28}$

At the moment, only two studies have investigated the long term effect of rhIGF1 therapy in IGFD patients: one by the European Study Group including 33 patients treated from 48 up to 72 months $^{29}$ and another by the American Study Group comprising 76 patients treated up to 12 years under a predominantly open label design. ${ }^{31}$

In the American study, height velocity increased from the pretreatment mean of $2.8 \mathrm{~cm} /$ year to an average of $8 \mathrm{~cm} /$ year in the first year. In children receiving higher dosage (at least $100 \mu \mathrm{g} / \mathrm{kg}$ twice a day) the average height velocity was $8.7 \mathrm{~cm} /$ year during the first year of therapy. From the second year of treatment the growth velocity greatly decelerated, although the mean growth rate remained significantly over the baseline growth ${ }^{31}$ (Table 2). The authors concluded that as the rhIGF1-treated subjects had grown at only near normal rates for age after the first year, it should be unlikely for them to reach regular adult height.

Moreover, children with IGFD treated with rhIGF1 in another study were compared with growth impairment-matched

Table 2 Results of long-term treatment with rhIGFI on growth velocity in primary IGF-I deficiency

\begin{tabular}{lll}
\hline $\begin{array}{l}\text { Years of } \\
\text { treatment }\end{array}$ & $\begin{array}{l}\mathbf{N} \\
\text { patients }\end{array}$ & $\begin{array}{l}\text { Growth velocity } \\
\text { (cm/year) }\end{array}$ \\
\hline 1 & 59 & 8.0 \\
2 & 54 & 5.9 \\
3 & 48 & 5.5 \\
4 & 39 & 4.8 \\
5 & 21 & 4.9 \\
6 & 20 & 5.0 \\
7 & 16 & 4.7 \\
8 & 14 & 4.6 \\
\hline
\end{tabular}

Abbreviations: IGF-I, insulin-like growth factor-I; rhIGFI, recombinant IGF-I.
GH-deficient children treated with rhGH. GH-deficient children showed an increase in growth velocity in the first and second year of $40 \%$ and $50 \%$, respectively. ${ }^{28}$ Thus, while growth velocity in children treated for GH deficiency remained constantly above the normal range, which generally allowed them to achieve normal adult height, this was not possible for IGFD patients, even when treated with a high dose of rhIGF1 for a long-term period.

Poor compliance to therapy in these patients has been reported to negatively affect treatment outcomes. ${ }^{28}$ Moreover, the different effect on growth rate in children with severe IGFD treated with rhIGF1 when compared to GH-deficient children treated with rhGH is likely due to the difficulty in replicating the physiological IGF-1 distribution and action with rhIGF1 treatment and to restore the direct effect of $\mathrm{GH}$ on growth and metabolism. In particular exogenous administration of rhIGF1 probably does not restore the local IGF-1 action and the paracrine effect of IGF-1 on condrocyte proliferation within the growth plate. ${ }^{32}$

It is worth noting that IGF-1 usually complexes with IGFBP-3 and $A L S$ that depend on GH level and action. The subcutaneously administration of rhIGF1 does not correct the low circulating levels of IGFBP-3 and $A L S$ and therefore the clearance of rhIGF1 is accelerated and the tissue distribution affected. ${ }^{33}$ Moreover, it has been described that prolonged administration of rhIGF1 leads to generation of IGFBP-3 and $A L S$ and other binding proteins, requiring sometimes a reduction of rhIGF1 dosage to prevent adverse effects. $^{2}$ The possible direct effect of GH on skeletal growth should also be considered. This can not be restored by administration of rhIGF1 alone.

Moreover, long-term treatment with mecasermin in children affected by severe primary IGFD has been reported to reduce adipose tissue, to improve bone density, and to stimulate erythropoiesis, monocyte blood counts and to reduce platelets to within the normal range. ${ }^{2,37}$ Furthermore this treatment has been reported to increase androgens in males and gonadotropins in adults. ${ }^{37}$

Preliminary uncontrolled studies, on treatment of IGFD with the complexes of IGF1/IGFBP-3 (mecasermin rinfabate), showed extension of serum IGF-1 half life and normalization of serum levels of IGF1, but failed to demonstrate an improvement in growth rate, compared to treatment with rhIGF1 alone. ${ }^{17,34}$

Unpublished data ${ }^{35}$ demonstrated that patients receiving rhIGF1/IGFBP-3 at a dose equivalent to a daily dose of rhIGF1 of $200 \mu \mathrm{g} / \mathrm{kg}$ showed an increase in height velocity only of $3 \mathrm{~cm} /$ year. Patients treated with higher dose of the 
complex comparable to $400 \mu \mathrm{g} / \mathrm{kg}$ of rhIGF1 per day showed an increment in growth rate of $6.3 \mathrm{~cm} /$ year. ${ }^{35}$

These data demonstrated that large amount of rhIGF1 are needed, when administered complexed with IGFBP-3, to obtain the growth response comparable to rhIGF1 alone. Furthermore, the effect on growth velocity rapidly diminished after the first year of treatment with progressive decrement as observed for rhIGF1 alone. ${ }^{4,17,35}$

Pharmacokinetic studies demonstrated a comparable concentration for circulating IGF-1 with twice a day rhIGF1 injections of $80 \mu \mathrm{g} / \mathrm{kg}$ and daily rhIGF1/IGFBP-3 in a dose either $0.5 \mathrm{mg} / \mathrm{kg}$ (equivalent to $100 \mu \mathrm{g} / \mathrm{kg}$ of $\mathrm{rhIGF} 1$ ) or $1 \mathrm{mg} / \mathrm{kg}$ (equivalent to $200 \mu \mathrm{g} / \mathrm{kg}$ of rhIGF1). The time of maximal concentration for rhIGF1 treatment alone was eight hours and for combination treatment was about 19 hours at the low dose and 15 hours at higher dose. The 24 hour area under the curve (AUC) was comparable between rhIGF1 therapy and the higher combination dose, while it was less for the lower combination dose. ${ }^{34}$

The comparable levels of circulating IGF-1 either in patients treated with rhIGF1 alone or with the complex, may be explained by the possible binding of IGF-1 to other IGFBPs. Indeed, IGFBP-2 is elevated in IGFD patients and increases with rhIGF1 therapy. ${ }^{36}$

In summary, rhIGF1 treatment in severe primary IGFD patients showed a prolonged effect on growth in all studies, particularly in long-term studies. Even if rhIGF1 treatment does not allow a normal catch-up growth to IGFD patients, especially when compared to GH therapy in GH-deficient children, it allows the achievement of an adult final height significantly greater than that expected in the absence of therapy.

It is still not known if the use of different dose regimens of rhIGF1 or new products, or an earlier start of treatment in children affected by IGFD, may help in the future to improve the height outcome of these patients.

\section{Adverse effects of therapy with rhIGF I}

Different adverse effects of rhIGF1 therapy are reported. They are summarized in Table 3 . The most common adverse event during treatment with rhIGF1 is hypoglycemia. While during GH treatment in GH-deficient patients hypoglycemic episodes decrease, in primary IGFD patients they can increase by the beginning of treatment.

Increased episodes of hypoglycemia can be explained by the fact that IGF-1 increases glucose muscle uptake and decreases hepatic glucose release, mimicking an insulinogenic effect. ${ }^{38}$
Table 3 Common adverse events reported during long-term treatment with rhIGFI in primary IGF-I deficiency

\begin{tabular}{ll}
\hline Adverse events & $\%$ \\
\hline Hypoglycemia & 49 \\
Hypoglycemic seizure & 5 \\
Hypoacusisa & 22 \\
Snoring & 22 \\
Tonsillar/adenoid hypertrophy & 22 \\
Tympanostomy tube placement & 16 \\
Sleep apnea & 4 \\
Tonsillectomy/adenoidectomy & 11 \\
Thymic hypertrophy & 35 \\
Lipohypertrophy & 32 \\
Orthopedic events & 20 \\
Intracranial hypertension & 4 \\
Nephrolithiasis & 3 \\
\hline
\end{tabular}

Abbreviations: IGF-I, insulin-like growth factor-I; rhIGFI, recombinant IGF-I.

In the largest long-term study available to date, hypoglycemia occurred in $49 \%$ of treated patients. ${ }^{31,39}$ It is worth noting that many patients manifested hypoglycemia even before the beginning of treatment. In a six month placebo-controlled study, an incidence of hypoglycemia of $67 \%$ in children receiving placebo was demonstrated versus $86 \%$ in children receiving rhIGF1 (the difference was not statistically significant). ${ }^{40}$ Younger subjects are usually more prone to develop hypoglycemia, especially when they are severely short with prior history of spontaneous hypoglycemia. ${ }^{31}$

Monitoring of blood glucose concentration by finger stick blood in 23 subjects residing in a research unit documented frequent hypoglycemia before breakfast and lunch before the beginning of rhIGF1 therapy. There was no increase of episodes of glycemic levels under $50 \mathrm{mg} / \mathrm{dl}$ after the initiation of treatment. Five subjects in a crossover placebo-controlled study were monitored three times a day for 15 months. The percentage of glucose levels under $50 \mathrm{mg} / \mathrm{dl}$ was $2.6 \%$ in placebo versus $5.5 \%$ in rhIGF1 patients (the difference was not statistically significant). ${ }^{31,39}$

Hypoglycemia seems to be less frequent in patients treated with combination of rhIGF1/rhIGFBP-3 with a reported frequency of $31 \% .{ }^{35}$ It seems reasonable that hypoglycemia can be easily controlled with adequate food intake before the rhIGF1 administration.

Lipohypertrophy at the site of injection is another common side adverse effect. It can decrease the effect of treatment and it is usually due to failure of rotation of injection sites. ${ }^{31}$ Hair growth at the injection site for rhIGF1/IGFBP-3 combination 
treatment and tachycardia for the inotropic effect of rhIGF1 are other adverse events described. ${ }^{41}$

Intracranial hypertension or papilledema have been described in about $5 \%$ of patients receiving mecasermin. Headache was more frequent.

Lymphoid tissue hypertrophy associated sometimes with partial hearing loss and snoring can occur in about $22 \%$ of patients. In $10 \%$ of these children tonsil/adenoid hypertrophy may require surgical intervention. Thymic enlargement is a common feature during rhIGF1 treatment, occurring in about $35 \%$ of subjects.

Some of the side effects may develop or increase during long-term treatment, ie, snoring was described as increasing from $4 \%$ during the first year of treatment to $65 \%$ in patients treated for longer periods. ${ }^{31}$

Acromegaloid features have also been reported in patients, especially those receiving mecasermin during puberty. ${ }^{31,39}$

Increase in body mass index (BMI) during treatment and in some case worsening of obesity has been described. ${ }^{29}$ It seems that in IGFD-treated children, the increase in BMI is due mainly to increase of fat mass, rather than increase of lean mass. ${ }^{2}$

The development of anti-IGF-1 antibodies during the therapy with rhIGF1 has been described. In the Chernausek study, ${ }^{31} 14$ out of 23 patients monitored showed positive anti-IGF-1 antibodies. No patients with positive antibodies showed statistically different growth rate compared to antibodies-negative patients during the first year of treatment.

The long-term influence of rhIGF1 therapy on cancer risk is still unknown. Moreover, the well known mitogenic effect of IGF-1 and the increased risk of neoplasia in subjects with elevated $\mathrm{GH}$ levels must be taken into account. ${ }^{42,43}$ Furthermore, aberrant tissue development in patients receiving rhIGF1 has been described. For all these reasons caution and long-term follow up is needed in IGFD children treated with mecasermin.

\section{Conclusion}

The availability of rhIGF1 for treatment of severe primary IGFD had improved the possibility for subjects affected by this rare condition to achieve higher adult height and to improve the outcomes of some of the clinical features of this syndrome.

Efficacy of rhIGF1 (mecasermin) therapy is not comparable to GH treatment in GHD children, with still poor results on final adult height. This may be due to our incomplete knowledge of the IGFD syndrome.

The new compound, the IGF1/IGFBP-3 (mecasermin rinfabate) has been used to improve the effect of rhIGF1 alone, but is no longer available due to the outcome of legal action in 2007.

To date the approved indication from FDA and EMEA for the use of mecasermin is severe short stature with very low IGF-1 levels and normal serum levels of GH or presence of GH antibodies. There is still no approval of rhIGF1 therapy for the treatment of children with failure of height gain with rhGH therapy.

rhIGF1 can not be a substitute for GH treatment in GH-deficient individuals. Mecasermin has not been approved yet for treatment of secondary forms of IGFD such as malnutrition, liver dysfunction, etc.

The very recent use of mecasermin for treatment of severe primary IGFD, the lack of long-term data and the possible new adverse events indicate the need of careful use of this drug for other indications. Many studies are ongoing at the moment to understand a better classification of IGFD, the possible utility of IGF-1 and IGFBP-3 generation test and the utility of combined therapy with rhGH and rhIGF1.

In the future, new indications for the use of rhIGF1 may be available and alternative uses in pathologies other than short stature and IGFD will have to be explored.

\section{Disclosure}

The authors report no conflicts of interest in this work.

\section{References}

1. Kronenberg H, Melmed S, Polonsky K, Larsen PR. Williams Textbook of Endocrinology. 11 th edition. Burlington, MA: Elsevier; 2007.

2. Laron Z. Laron syndrome (primary growth hormone resistance or insensitivity): the personal experience 1958-2003. J Clin Endocrinol Metab. 2004;89(3):1031-1044.

3. Norman P. Mecasermin Tercica. Curr Opin Investig Drugs. 2006;7(4): 371-380.

4. Rosenbloom AL. Mecasermin (Recombinant Human Insulin-like Growth Factor I). Adv Ther. 2009;26(1):40-54.

5. Berg MA, Peoples R, Pérez-Jurado L, et al. Receptor mutations and haplotypes in growth hormone receptor deficiency: a global survey and identification of the Ecuadorean E180splice mutation in an oriental Jewish patient. Acta Paediatr Suppl. 1994;399:112-114.

6. Rosenfeld RG. Molecular mechanisms of IGF-I deficiency. Horm Res. 2006;65(Suppl 1):15-20.

7. Rosenfeld RG, Belgorosky A, Camacho-Hubner C, Savage MO, Wit JM, Hwa V. Defects in growth hormone receptor signaling. Trends Endocrinol Metab. 2007;18(4):134-141.

8. Woods KA, Camacho-Hübner C, Savage MO, Clark AJ. Intrauterine growth retardation and postnatal growth failure associated with deletion of the insulin-like growth factor I gene. N Engl J Med. 1996;335(18): 1363-1367.

9. Domené HM, Bengolea SV, Martínez AS, et al. Deficiency of the circulating insulin-like growth factor system associated with inactivation of the acid-labile subunit gene. N Engl J Med. 2004;350(6):570-577.

10. Savage MO, Attie KM, David A, Metherell LA, Clark AJ, CamachoHübner C. Endocrine assessment, molecular characterization and treatment of growth hormone insensitivity disorders. Nat Clin Pract Endocrinol Metab. 2006;2(7):395-407. 
11. Laron Z. Natural history of the classical form of primary growth hormone $(\mathrm{GH})$ resistance (Laron syndrome). J Pediatr Endocrinol Metab. 1999;12(Suppl 1):231-249.

12. Bachrach LK, Marcus R, Rosenbloom AL, et al. Bone mineral, histomorphometry, and body composition in adults with growth hormone receptor deficiency. J Bone Miner Res. 1998;13(3):415-421.

13. Benbassat CA, Eshed V, Kamjin M, Laron Z. Are adult patients with Laron syndrome osteopenic? A comparison between dual-energy X-ray absorptiometry and volumetric bone densities. J Clin Endocrinol Metab. 2003;88(10):4586-4589.

14. Laron Z, Sarel R, Pertzelan A. Puberty in Laron type dwarfism. Eur J Pediatr. 1980;134(1):79-83.

15. Rosenbloom AL, Guevara-Aguirre J, Rosenfeld RG, Francke UG. Growth hormone receptor deficiency in Ecuador. J Clin Endocrinol Metab. 1999;84:4436-4443.

16. Rosenbloom AL. Recombinant human insulin-like growth factor I (rhIGF-I) and rhIGF-I/rhIGF-binding-protein-3: new growth treatment options? J Pediatr. 2007;150(1):7-11.

17. Rosenbloom AL. The role of recombinant insulin-like growth factor I in the treatment of the short child. Curr Opin Pediatr. 2007;19(4): 458-464.

18. Laron Z, Avitzur Y, Klinger B. Carbohydrate metabolism in primary growth hormone resistance (Laron syndrome) before and during insulinlike growth factor-I treatment. Metabolism. 1995;44(10 Suppl 4): 113-118.

19. Collett-Solberg PF, Misra M; Drug and Therapeutics Committee of the Lawson Wilkins Pediatric Endocrine Society. The role of recombinant human insulin-like growth factor-I in treating children with short stature. J Clin Endocrinol Metab. 2008;93(1):10-18.

20. Keret R, Pertzelan A, Zeharia A, Zadik Z, Laron Z. Growth hormone $(\mathrm{hGH})$ secretion and turnover in three patients with Laron-type dwarfism. Isr J Med Sci. 1988;24(2):75-79.

21. Buckway CK, Guevara-Aguirre J, Pratt KL, Burren CP, Rosenfeld RG. The IGF-I generation test revisited: a marker of GH sensitivity. J Clin Endocrinol Metab. 2001;86(11):5176-5183.

22. Blair JC, Camacho-Hübner C, Miraki Moud F, et al. Standard and low-dose IGF-I generation tests and spontaneous growth hormone secretion in children with idiopathic short stature. Clin Endocrinol (Oxf). 2004;60(2):163-168.

23. Selva KA, Buckway CK, Sexton G, et al. Reproducibility in patterns of IGF generation with special reference to idiopathic short stature. Horm Res. 2003;60(5):237-246.

24. Fassone L, Corneli G, Bellone S, et al. Growth hormone receptor gene mutations in two Italian patients with Laron syndrome. $J$ Endocrinol Invest. 2007;30(5):417-420.

25. Milani D, Carmichael JD, Welkowitz J, et al. Variability and reliability of single serum IGF-I measurements: impact on determining predictability of risk ratios in disease development. J Clin Endocrinol Metab. 2004;89(5):2271-2274.

26. Khosravi J, Diamandi A, Bodani U, Khaja N, Krishna RG. Pitfalls of immunoassay and sample for IGF-I: comparison of different assay methodologies using various fresh and stored serum samples. Clin Biochem. 2005;38(7):659-666.

27. Laron Z, Anin S, Klipper-Aurbach Y, Klinger B. Effects of insulin-like growth factor on linear growth, head circumference, and body fat in patients with Laron-type dwarfism. Lancet. 1992;339(8804):1258-1261.
28. Guevara-Aguirre J, Rosenbloom AL, Vasconez O, et al. Two-year treatment of growth hormone $(\mathrm{GH})$ receptor deficiency with recombinant insulin-like growth factor I in 22 children: comparison of two dosage levels and to GH-treated GH deficiency. J Clin Endocrinol Metab. 1997;82(2):629-633.

29. Ranke MB, Savage MO, Chatelain PG, Preece MA, Rosenfeld RG, Wilton P. Long-term treatment of growth hormone insensitivity syndrome with IGF-I. Results of the European Multicentre Study. The Working Group on Growth Hormone Insensitivity Syndromes. Horm Res. 1999;51(3):128-134.

30. Backeljauw PF, Underwood LE. Therapy for 6.5-7.5 years with recombinant insulin-like growth factor I in children with growth hormone insensitivity syndrome: a clinical research center study. J Clin Endocrinol Metab. 2001;86(4):1504-1510.

31. Chernausek SD, Backeljauw PF, Frane J, Kuntze J, Underwood LE. Long-term treatment with recombinant insulin-like growth factor (IGF)-I in children with severe IGF-I deficiency due to growth hormone insensitivity. J Clin Endocrinol Metab. 2007;92(3):902-910.

32. Le Roith D, Bondy C, Yakar S, Liu JL, Butler A. The somatomedin hypothesis: 2001. Endocr Rev. 2001;22(1):53-74.

33. Savage MO, Blair JC, Jorge AJ, Street ME, Ranke MB, Camacho-Hübner C IGFs and IGFBPs in GH insensitivity. Endocr Dev. 2005;9:100-106.

34. Camacho-Hübner C, Rose S, Preece MA, et al. Pharmacokinetic studies of recombinant human insulin-like growth factor I (rhIGF-I)/ rhIGF-binding protein-3 complex administered to patients with growth hormone insensitivity syndrome. J Clin Endocrinol Metab. 2006;91(4): 1246-1253.

35. Camacho-Hubner C, Underwood LE, Yordam N, et al. Once daily rhIGF-1/rhIGFBP-3 treatment improves growth in children with severe primary IGF-1 deficiency: results of a multicenter clinical trial [abstract]. Endocrine Society's Annual Meeting, June 27, 2006; Boston, MA.

36. Vaccarello MA, Diamond FB Jr, Guevara-Aguirre J, et al. Hormonal and metabolic effects and pharmacokinetics of recombinant insulinlike growth factor-I in growth hormone receptor deficiency/Laron syndrome. J Clin Endocrinol Metab. 1993;77(1):273-280.

37. Sivan B, Lilos P, Laron Z. Effects of insulin-like growth factor-I deficiency and replacement therapy on the hematopoietic system in patients with Laron syndrome (primary growth hormone insensitivity). $J$ Pediatr Endocrinol Metab. 2003;16(4):509-520.

38. Guler HP, Zapf J, Froesch ER. Short-term metabolic effects of recombinant human insulin-like growth factor I in healthy adults. $N$ Engl $J$ Med. 1987;317(3):137-140.

39. Chernausek SD. Growth hormone-resistant syndromes: long-term follow-up. Endocr Dev. 2009; 14:135-142.

40. Guevara-Aguirre J, Vasconez O, Martinez V, et al. A randomized, double blind, placebo-controlled trial on safety and efficacy of recombinant human insulin-like growth factor-I in children with growth hormone receptor deficiency. J Clin Endocrinol Metab. 1995;80(4):1393-1398.

41. Vasconez O, Martinez V, Martinez AL, et al. Heart rate increases in patients with growth hormone receptor deficiency treated with insulinlike growth factor I. Acta Paediatr Suppl. 1994;399:137-139.

42. Perry JK, Emerald BS, Mertani HC, Lobie PE. The oncogenic potential of growth hormone. Growth Horm IGF Res. 2006;16(5-6):277-289.

43. Samani AA, Yakar S, LeRoith D, Brodt P. The role of the IGF system in cancer growth and metastasis: overview and recent insights. Endocr Rev. 2007;28(1):20-47.
Therapeutics and Clinical Risk Management

\section{Publish your work in this journal}

Therapeutics and Clinical Risk Management is an international, peerreviewed journal of clinical therapeutics and risk management, focusing on concise rapid reporting of clinical studies in all therapeutic areas, outcomes, safety, and programs for the effective, safe, and sustained use of medicines. This journal is indexed on PubMed Central, CAS,

\section{Dovepress}

EMBase, Scopus and the Elsevier Bibliographic databases. The manuscript management system is completely online and includes a very quick and fair peer-review system, which is all easy to use. Visit http://www.dovepress.com/testimonials.php to read real quotes from published authors. 